\title{
Artificial Intelligence Based Prediction of Seawater Level: A Case Study for Bosphorus Strait
}

\author{
Yavuz Karsavran \\ Hydraulics and Water Resources Department, \\ Istanbul Technical University, Maslak, Istanbul, Turkey. \\ Corresponding author: karsavran@itu.edu.tr \\ Tarkan Erdik \\ Hydraulics and Water Resources Department, \\ Istanbul Technical University, Maslak, Istanbul, Turkey. \\ E-mail: erdik@itu.edu.tr
}

(Received on April 1, 2021; Accepted on June 29, 2021)

\begin{abstract}
Sea level prediction is an important phenomenon for making reliable oceanographic and ship traffic management decisions especially for Bosphorus Strait that has no permanent sea level measurement stations due to high cost. This study presents artificial intelligence (AI) techniques, such as Artificial Neural Networks (ANNs) and Support Vector Machines (SVM) to predict the seawater level in the Bosphorus Strait. In addition, the Multiple Linear Regression model (MLR) is constructed and employed as a benchmark. The dataset employed in developing the models are wind speed, atmospheric pressure, water surface salinity, and temperature data, which were measured between September 2004 and January 2006. The results reveal that all ANN and SVM models outperform MLR and can predict the water levels quite accurately. ANN has a better performance than SVM for predicting sea level in the Bosphorus by coefficient of correlation $(R)=0.76$ and root mean square error $(R M S E)=0.059$. Moreover, the influence of the Danube River discharge in the prediction is investigated in the present study. The discharge of the Danube River by the lag time of 70 days yields the highest performance on ANN by increasing R to 0.82 and decreasing RMSE to 0.048 .
\end{abstract}

Keywords- Seawater level prediction, Artificial intelligence, ANN, SVM, Bosphorus strait, Danube River.

\section{Introduction}

Bosphorus is a natural strait, located in northwestern Turkey, which connects the Black Sea and Mediterranean Sea (Figure 1). It is the only way for Bulgaria, Georgia, Romania, Russia (SouthWestern part) and Ukraine to reach the world's oceans (through Mediterranean). It has played a significant role in world maritime trade. It is one of the busiest shipping lanes in the world and around 48000 ships pass through that strait annually, which is reportedly three and four times denser than the traffic of Suez Canal and the Panama Canal (Ergocun, 2019; Sacu et al., 2020a; Sacu et al., 2020b; Sacu et al., 2021; Smith, 2015).

Bosphorus has a length of 31 kilometers and a width that varies between 730-3300 meters. The water depth varies between 30 and $100 \mathrm{~m}$. Its complicated geometry makes the Bosphorus Strait as one of the world's most difficult waterways to navigate. The strait is only half a mile wide at the narrowest cross section, posing an obstacle to the oil tankers and other vessels using the strait. In addition, the extremely fast current in the strait, which is controlled by the water level differences at both end of the strait, makes it even more difficult to navigate. Current velocity reaches maximum 

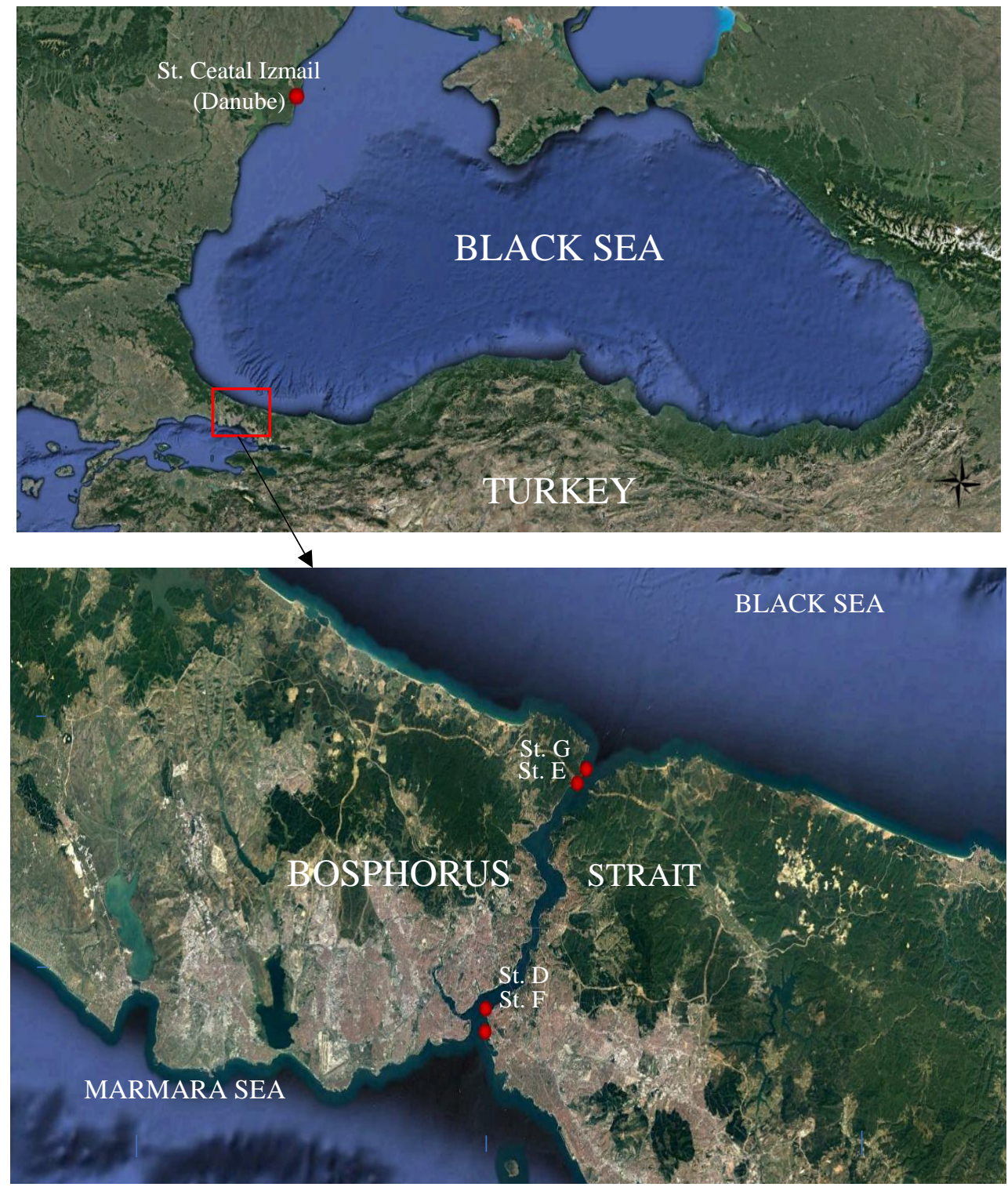

Figure 1. The aerial view of the Bosphorus Strait and the locations of the measurement stations in Bosphorus Strait.

up to $2 \mathrm{~m} / \mathrm{s}$ in the narrowest section of the Bosphorus (Ozsoy et al., 1998). Sea level prediction is important to make ship traffic management strategies in the Bosphorus Strait, which might cause extreme resistance to a hull when moving against the water, especially for those ships moving to Black Sea. In addition, sea level prediction has significant influence on the planning and application of sea projects that are connected to transportation (Whittington, 2016), coastal management (Pethick, 2001), environmental pollution (Maderich and Konstantinov, 2002). However, sea level prediction is still inadequate because of the limited observed data (Altunkaynak and Kartal, 2021; Anderson, 2013; Hil, 2020). 
In recent years, many techniques have been employed to predict water level on water bodies. Those techniques mainly employ data-driven approaches, which are suited to resolve complex problems. In those approaches, the statistical distribution of the data need not to be known and nonstationarities in the data, such as trends and seasonal variations, are implicitly included in the architecture of the model constructed (Kisi and Cigizoglu, 2007).

Altunkaynak et al. (2003) are amongst the first who applied the triple diagram method (TDM) to forecast monthly water level fluctuations of Lake Van in Turkey. Later, Altunkaynak and Sen (2007) used the fuzzy logic model to predict the water level of Lake Van. Makarynska and Makarynskyy (2008) predicted seawater level changes from one hour to five days by using artificial neural network (ANN) models by using hourly observed data from a tide gauge in Cocos Island, India. Sertel et al. (2008) predicted the daily mean sea level height on the basis of the observed data from January 1991 to December 2005 by using ANN. Karimi et al. (2013) predicted sea level changes dependent upon the hourly sea level changes in Darwin Harbour, Australia, by applying ANN. Altunkaynak (2014) predicted water level fluctuations in Lake Michigan - Huron by using wavelet-expert system methods. Altunkaynak and Kartal (2019) predicted the daily Bosphorus seawater level by combining wavelet transform to the fuzzy logic model. They achieved to predict sea level accurately with extended lead times up to 7 days. Altunkaynak (2019) applied the hybrid season-neuro approach to forecast the water level of Lake Van. Khaledian et al. (2020) applied support vector machine (SVM) and ANN to predict the Caspian Sea water level. Finally, Altunkaynak and Kartal (2021) predicted future sea level lead time up to 7 days of Bosphorus Strait by machine learning models.

The sea level variations in the Bosphorus Strait are highly dependent on hydrological, meteorological, and oceanographical conditions such as precipitation, evaporation, temperature, water salinity (Jarosz et al., 2011; Karsavran et al., 2020; Sacu et al., 2020a; Sacu et al., 2020b; Sacu et al., 2021; Yuksel et al., 2008). In this study, ANN and SVM models are constructed and compared to predict northern seawater level in the chaotic Bosphorus Strait using meteorological and oceanographical measured data. In addition, MLR models are constructed and employed as a benchmark. The constructed models are compared with each other and best model architecture is selected. Later, the influence of Danube River discharge, about $500 \mathrm{~km}$ away, is investigated on the seawater level in Bosphorus by using different lag times.

\section{Methodology}

\subsection{Artificial Neural Networks}

ANN is a group of small individually related processing units that pass the information into along interconnections. An ANN is inspired by the biological neural network functions like the human brain and the human nervous system. The multilayer perceptron (MLP) technique in ANN (Figure 2), which has been used for predictions in many areas of engineering and science since the 1990s (Chau and Cheng, 2002), consists of at least three layers of interconnected neurons. The first layer is the input layer, which accepts external data, and the last layer is the output layer that produces the results of the MLP model. The layer between the input and output layers is called the hidden layer, where artificial neurons acquire weighted inputs and add a bias value. 


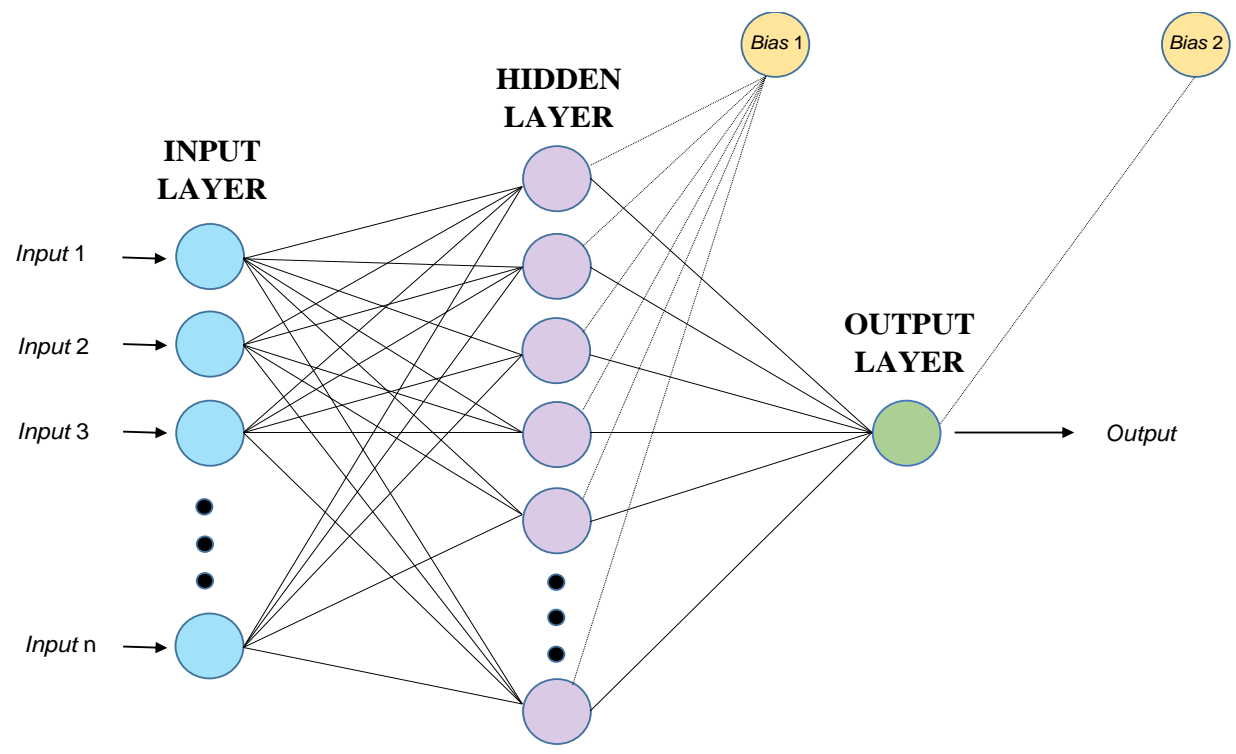

Figure 2. Multilayer perceptron (MLP) technique in ANN.

For an ANN to create an output vector $z_{k}$ as near as possible to the target vector $t_{k}$, the backpropagation algorithm is applied to decide the values of weights and biases to minimize a predetermined error function (E) (ASCE Task Committee, 2000), which is defined as:

$E=\sum_{P} \sum_{p}\left(z_{k}-t_{k}\right)^{2}$

where $P$ : number of training patterns; $p$ : number of output neurons.

The back-propagation algorithm acts two phases of data flow. First of all, the inputs proceed into the network from the input layer to the output layer. Finally, the network creates an output vector, which is compared with the desired target vector, and an error is calculated by using Equation (1). At that point, the error signals are back-propagated from the output layer to the previous layers to update their weights based on Equation (2):

$\Delta w_{i j}(n)=\alpha^{\prime} \Delta w_{i j}(n-1)-\varepsilon\left(\frac{\partial E}{\partial w_{i j}}\right)$

where $\Delta w_{i j}(n)$ and $\Delta w_{i j}(n-1)$ are the weight increments between the input and hidden layers during the nth and (n-1)th steps, $\alpha^{\prime}$ is the momentum factor that speeds up training and helps prevent oscillations, and $\varepsilon$ is the learning rate that increases the chance of avoiding the training process being trapped in a local minimum instead of global minima (ASCE Task Committee, 2000). The training process is propagated until the predicted outputs and target answers equal within a given tolerance (Lin and Lee, 1996).

\subsection{Support Vector Machines}

SVM states of neural network technology based on statistical learning techniques (Vapnik, 1995; 1998). The main idea of SVM is to use a linear model to put nonlinear class boundaries into some nonlinear mapping of the input vector into the high-dimensional feature space. The linear model built in the new space can depict a nonlinear solution boundary in the original space (Wang et al., 2009). 
Given the training data set $\left\{\left(x_{i}, d_{i}\right)\right\}_{i}^{n}$, where $x_{i}=$ input vector, $d_{i}=$ desired value, $n=$ total number of data samples, $i=1,2, \ldots, \mathrm{n}$. The regression function of SVM is presented in Equation (3) (Wang et al., 2009).

$f(x)=w_{i} \cdot \varphi(x)+b$

where $w_{i}=$ weight, $\varphi(x)=$ feature of inputs and $b=$ threshold coefficients. The optimal objective function is shown in Equation (4).

$\min R=\frac{1}{2}\|w\|^{2}+\sum_{i=1}^{t}\left(\xi_{i}+\xi_{i}^{*}\right) \cdot C$

The constraint conditions are depicted in Equation (5):

Subject to $\left\{\begin{array}{c}f\left(x_{i}\right)-y_{i} \leq \varepsilon+\xi_{i} \\ y_{i}-f\left(x_{i}\right) \leq \varepsilon+\xi_{i}^{*} \\ \xi_{i} \geq 0, \xi_{i}^{*} \geq 0, i=1,2, \ldots, n\end{array}\right.$

where $\xi_{i}$ and $\xi_{i}^{*}$ are relaxation numbers. If there are some prediction errors, both of them will be greater than zero, if not, both of them will be zero. $C=$ parameter to decrease the fitting error, $\varepsilon=$ allowable error (Lin et al., 2020).

The Lagrangian form is used to solve this optimization problem. The equation is presented in Equation (6).

$L=\frac{1}{2}\|w\|^{2}+\sum_{i=1}^{n}\left(\xi+\xi_{i}^{*}\right) \cdot C-\sum_{i=1}^{n}\left(\mu_{i}^{*} \xi_{i}^{*}+\mu_{i} \xi_{i}\right)+\sum_{i=1}^{n} \alpha_{i}\left(f\left(x_{i}\right)-y_{i}-\varepsilon-\xi_{i}\right)+$

$+\sum_{i=1}^{n} \alpha_{i}^{*}\left(y_{i}-f\left(x_{i}\right)-\varepsilon-\xi_{i}^{*}\right)$

where $\mu_{i}, \mu_{i}^{*}, \alpha_{i}, \alpha_{i}^{*}$ : the lagrangian constants. When taken partial derivation of Equation (6) and presented the kernel function $K\left(x, x_{i}\right)=\exp \left(-\frac{\left\|x-x_{i}\right\|}{2 \sigma}\right)$ the non-linear fitting function becomes as in Equation (7) (Lin et al., 2020).

$f(x)=\sum_{i=1}^{n}\left(\alpha_{i}^{*}-\alpha_{i}\right) K\left(x, x_{i}\right)+b$

\subsection{Multiple Linear Regression}

Regression is one of the widely employed methods for prediction, optimization, process control, and other engineering activities. Mostly, the correlation between independent and dependent variables is explained by the regression model. In the simple linear regression, one dependent variable is related to one independent variable. However, there is more than one independent variable in many empirical models (Montgomery et al., 2009). So, the Multiple Linear Regression (MLR) model is used for the models that have more than one independent variable and makes the regression model very flexible. The general MLR is represented by Equation (8):

$Y=\beta_{0}+\beta_{1} X_{1}+\beta_{2} X_{2}+\cdots+\beta_{n} X_{n}$

where $Y=$ dependent variable, $X_{i}=$ independent variable, $\beta_{i}=$ regression coefficient. The MLR aims to discover an approximation function for the prediction of the system outputs (Kim et al., 2010).

\subsection{Model Evaluation Criteria}

The performances of the proposed models are achieved in terms of two different numerical error statistics (Equations 9-10), such as the coefficient of correlation $(R)$ and the root mean square error 
(RMSE). R describes the degree of collinearity between forecasted and observed data, which ranges from -1 to 1 . If $R=0$, no relationship exists. If $R=1$ or -1 , a perfect positive or negative linear relationship exists. $R$ has been used widely for model evaluation (Erdik et al., 2009; Lin et al., 2006; Wang et al., 2009). The root mean square error (RMSE) is often used for measuring the difference between forecasted and observed values (Lin et al., 2006; Wang et al., 2009). Those statistics are given below:

$R=\frac{\frac{1}{n} \sum_{i=1}^{n}\left(W L_{o}(i)-W L_{0}^{\prime}\right)\left(W L_{f}(i)-W L_{f}^{\prime}\right)}{\sqrt{\frac{1}{n} \sum_{i=1}^{n}\left(W L_{o}(i)-W L_{0}^{\prime}\right)^{2}} \cdot \sqrt{\frac{1}{n} \sum_{i=1}^{n}\left(W L_{f}(i)-W L_{f}^{\prime}\right)^{2}}}$

$R M S E=\sqrt{\frac{1}{n} \sum_{i=1}^{n}\left(W L_{f}(i)-W L_{o}(i)\right)^{2}}$

where $W L_{o}(i)$ and $\left(W L_{f}(i)\right.$ are observed and forecasted surface water level, respectively. $W L_{0}^{\prime}$ and $W L_{f}^{\prime}$ depicts their averages, and $\mathrm{n}$ is the number of data.

\section{Data and Study Area}

This study is based on continuous measurements carried out by the TAISEI Corporation, Japan, on behalf of the Republic of Turkey, Ministry of Environment and Urbanization (RTMEU, 2005). The data was measured between September 2004 and January 2006 for 15 months. Water elevation measurements at both ends of the Bosphorus (stations D and E) are collected at hourly intervals for the same period. Besides water level, water surface salinity and temperature were measured hourly in St. E and St. D. The wind speed and atmospheric pressure were measured on weather stations F and $\mathrm{G}$ at both ends of the Bosphorus Strait. Additionally, Danube River discharge data were obtained from the Ceatal Izmail Station for the same period at daily intervals. An aerial view of the Bosphorus Strait and the measurement locations are demonstrated in Figure 1. All of the data measurements and related information are depicted in Table 1.

Table 1. Measurement locations and durations.

\begin{tabular}{|c|c|c|c|c|}
\hline Stations & Measured Period & Measured Characteristics & Time Interval & Locations \\
\hline St. E & $\begin{array}{l}22.09 .04- \\
05.01 .06\end{array}$ & $\begin{array}{l}\text { Water level, } \\
\text { water surface salinity } \\
\text { and temperature }\end{array}$ & Hour & $\begin{array}{l}41^{0} 12,13^{\prime \prime}, \mathrm{N} \\
29^{0} 05^{\prime} 54^{\prime \prime} \mathrm{E}\end{array}$ \\
\hline St. G & $\begin{array}{l}19.11 .04- \\
05.01 .06\end{array}$ & $\begin{array}{l}\text { Wind speed, } \\
\text { air pressure }\end{array}$ & 10 minutes & $\begin{array}{c}41^{0} 24^{\prime \prime} \mathrm{N} \\
29^{0} 6^{\prime} \mathrm{E}\end{array}$ \\
\hline St. D & $\begin{array}{l}25.09 .04- \\
05.01 .06\end{array}$ & $\begin{array}{l}\text { Water level, } \\
\text { water surface salinity } \\
\text { and temperature }\end{array}$ & hour & $\begin{array}{l}41^{\circ} 01^{\prime} 31.4^{\prime \prime} \mathrm{N}, \\
29^{0} 00^{\prime} 30.3^{\prime \prime} \mathrm{E}\end{array}$ \\
\hline St. F & $\begin{array}{l}18.11 .04- \\
04.01 .06\end{array}$ & $\begin{array}{l}\text { Wind speed, } \\
\text { air pressure }\end{array}$ & 10 minutes & $\begin{array}{l}41^{0} 00,32.2^{\prime \prime} \mathrm{N}, \\
29^{0} 00^{\prime} 07.02^{\prime \prime} \mathrm{E}\end{array}$ \\
\hline St. Ceatal Izmail & $\begin{array}{l}01.01 .04- \\
31.12 .05\end{array}$ & Discharge & daily & $\begin{array}{l}45^{0} 21^{\prime} 67^{\prime \prime} \mathrm{N}, \\
28^{0} 71^{\prime} 67^{\prime}, \mathrm{E}\end{array}$ \\
\hline
\end{tabular}

To understand the sensitivity of the independent variables over the dependent variable, the Pareto chart is employed. The Pareto chart (Figure 3) depicts the absolute value of the t values of the estimated coefficients, which is useful to understand the relative importance of the parameters (Erdik and Pektas, 2019; Okcu et al., 2016). A total of 14 parameters are included in the pareto chart: those defined in Table 1 (except St. Ceatal Izmail) and the salinity difference (St. D salinitySt. E salinity) and temperature differences (St. D temperature- St. E temperature) at both ends of 
the Bosphorus.

The most effective parameters on the predicted sea level of the northern end of Bosphorus are found to be water temperature difference (WTD) and water salinity difference (WSD) between station D and $\mathrm{E}$ by 5.15 and $4.61 \mathrm{t}$-values, respectively. The other influential parameters compared to the others are air pressure at station F (APF), air pressure at station G (APG), northern wind gust at station G (NWGG) and northern wind gust at station F (NWGF). A total of 11 input sets are developed for the ANN, SVM and MLR models in Table 2. In the present study, $70 \%$ of total data were used for training and the remaining $30 \%$ for testing of all models. The division of data was done randomly, and the same training and test data were used for each model run.

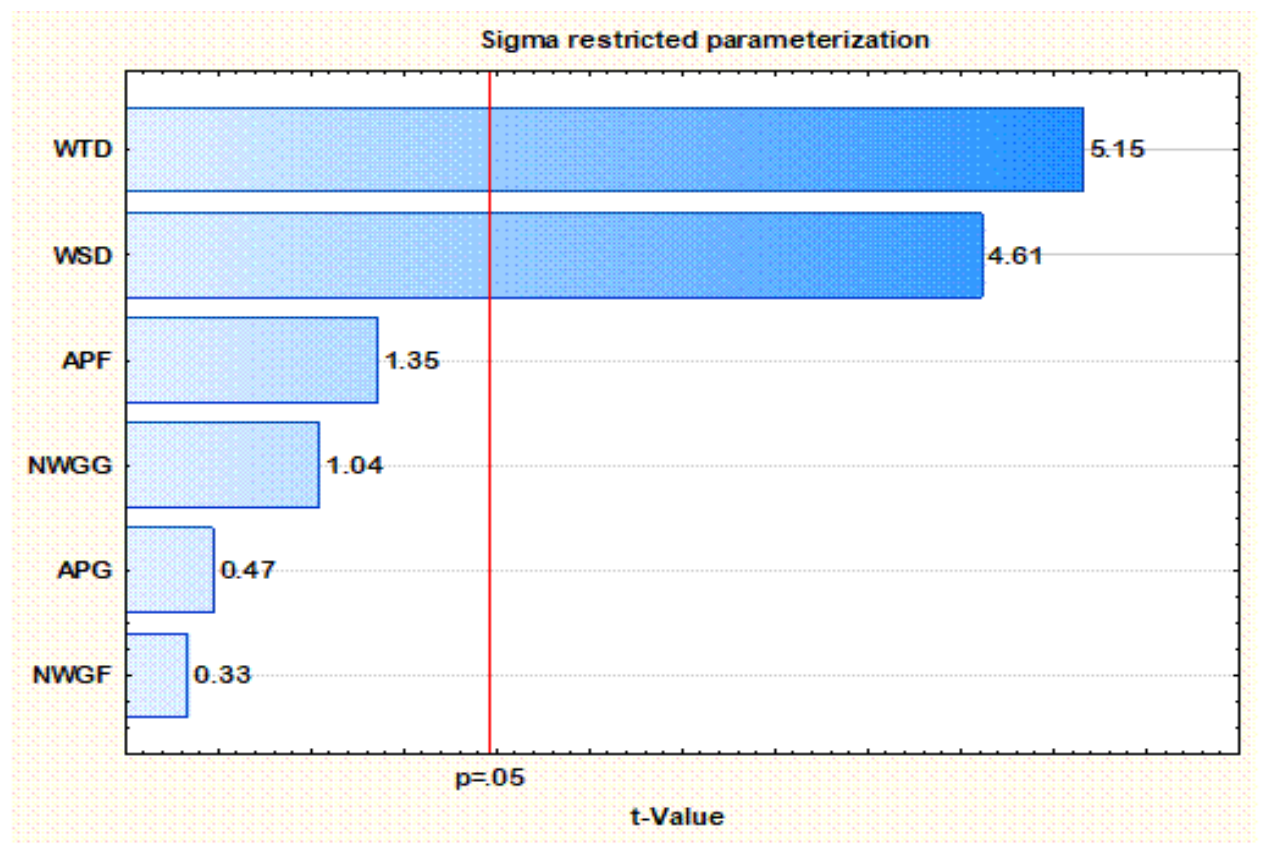

Figure 3. Pareto chart of the MLR model.

Table 2. Input set parameters.

\begin{tabular}{|l|l|}
\hline Input Set Name & Parameters \\
\hline Set 1 & WTD, WSD, APF, NWGG, NWGF \\
\hline Set 2 & WTD, WSD, APF, APG, NWGG \\
\hline Set 3 & WTD, WSD, NWGG, NWGF \\
\hline Set 4 & WTD, WSD, NWGF \\
\hline Set 5 & WTD, WSD, APG, NWGG, NWGF \\
\hline Set 6 & WTD, WSD, NWGG \\
\hline Set 7 & WTD, WSD, APF, NWGG \\
\hline Set 8 & WTD, WSD, APF, APG, NWGG, NWGF \\
\hline Set 9 & WTD, WSD, APF, APG, NWGF \\
\hline Set 10 & WTD, WSD, APF \\
\hline Set 11 & WTD, WSD, APG \\
\hline
\end{tabular}




\section{Application and Results}

Various ANN models are developed by using the input sets in Table 2. A total of 12 nodes are employed in the hidden layer. The optimum number of nodes were determined using a trial and error approach (Kim et al., 2013; Kisi, 2007; Seo et al., 2015). The number of hidden nodes was determined by systematically increasing the number of nodes from 1 to 12 until the network performance was not improved any more. The optimal structure of ANN was determined for the input Set 4 (3-8-1), with correlation coefficient $(R)=0.76$ and root mean square error $(R M S E)=$ 0.0587 (Table 3). Herein, the numbers of net name 3-8-1 depict an ANN model that has 3 input (WTD, WSD, NWGF), 8 hidden and 1 output nodes, respectively. In the present study, ANN models were trained with the Vanilla-Standard backpropagation. Many activation functions of hidden and output neurons from logsig, tansig to purelin are tried.

Table 3. Comparison of ANN input sets performance.

\begin{tabular}{|c|c|c|c|}
\hline Net Name & Input Sets & RMSE & R \\
\hline $3-8-1$ & SET4 & 0.0587 & 0.76 \\
\hline $5-7-1$ & SET1 & 0.0595 & 0.75 \\
\hline $5-4-1$ & SET2 & 0.0613 & 0.74 \\
\hline $4-9-1$ & SET3 & 0.0615 & 0.74 \\
\hline $5-11-1$ & SET5 & 0.0614 & 0.73 \\
\hline $4-6-1$ & SET7 & 0.0616 & 0.73 \\
\hline $3-8-1$ & SET6 & 0.0616 & 0.73 \\
\hline $5-11-1$ & SET9 & 0.0620 & 0.73 \\
\hline $6-10-1$ & SET8 & 0.0620 & 0.73 \\
\hline $3-10-1$ & SET10 & 0.0621 & 0.73 \\
\hline $3-4-1$ & SET11 & 0.0632 & 0.72 \\
\hline
\end{tabular}

The results of sea level prediction with designated input compounds (Table 2) are demonstrated in Table 4 by using SVM with the optimal Kernel function. A Kernel function must be chosen from the qualified functions (Dibike et al., 2001; Wang et al., 2009). Most of the works on the use of SVM on coastal modeling and forecasting have demonstrated the favorable performance of the Radial Basis Function (RBF, Lin et al., 2006; Wang et al., 2009). Therefore, the RBF is used as the Kernel function for the prediction of surface sea level in the present study. There are three parameters of RBF Kernels: C, $\varepsilon$ and $\sigma$, which affect the accuracy of an SVM model. The SCE UA (shuffled complex evolution - University of Arizona) method is employed to optimize the parameters of SVM (Duan et al., 1993). An extra presentation of SCE UA can be found by Lin et al. (2006). The RMSE is used to reach a suitable choice of these parameters and $\mathrm{C}, \varepsilon, \sigma$ are obtained as 19.27, 0.1, 0.33 for the Bosphorus. The highest performance of SVM is found with correlation coefficient $R=0.72$ and $R M S E=0.0608$ (Table 4).

The constructed MLR models are given in Table 5. In practical engineering applications, "parsimonious" models are preferable (Sen and Erdik, 2010). Therefore, the model obtained with four input variables, defined as SET 7 in Table 2, is suggested. The resulting model is: $W L E=1.2230+0.0139 W S D+0.0199 W T D-0.0015 N W G G-0.0009 A P F$

where WLE: water level of St. E - Northern Bosphorus. The performance of best model is $R=0.63$ and $R M S E=0.0701$. The normality assumption that the underlying residuals (observed minus predicted values) are normally distributed is not violated in regression models in Table 5. In addition, MLR models are checked for collinearity. The most apparent difference is that the Variance Inflation Factors (VIFs) are all less than 5, which is a clear indication that there is no multi-collinearity in the dataset. 
Table 4. Comparison of SVM input sets performance.

\begin{tabular}{|c|c|c|c|}
\hline Models & Input Sets & RMSE & R \\
\hline SVM & SET 10 & 0.0608 & 0.72 \\
\hline SVM & SET 11 & 0.0610 & 0.72 \\
\hline SVM & SET 5 & 0.0616 & 0.71 \\
\hline SVM & SET 1 & 0.0616 & 0.71 \\
\hline SVM & SET6 & 0.0620 & 0.70 \\
\hline SVM & SET 7 & 0.0622 & 0.70 \\
\hline SVM & SET 3 & 0.0628 & 0.70 \\
\hline SVM & SET 4 & 0.0630 & 0.69 \\
\hline SVM & SET 2 & 0.0632 & 0.69 \\
\hline SVM & SET 8 & 0.0634 & 0.69 \\
\hline SVM & SET9 & 0.0637 & 0.68 \\
\hline
\end{tabular}

Table 5. Comparison of MLR input sets performance.

\begin{tabular}{|c|c|c|c|}
\hline Models & Input Sets & RMSE & R \\
\hline MLR & SET 8 & 0.0701 & 0.63 \\
\hline MLR & SET 2 & 0.0701 & 0.63 \\
\hline MLR & SET 1 & 0.0701 & 0.63 \\
\hline MLR & SET 7 & 0.0701 & 0.63 \\
\hline MLR & SET9 & 0.0702 & 0.63 \\
\hline MLR & SET 5 & 0.0703 & 0.63 \\
\hline MLR & SET 10 & 0.0704 & 0.62 \\
\hline MLR & SET 11 & 0.0705 & 0.62 \\
\hline MLR & SET6 & 0.0706 & 0.62 \\
\hline MLR & SET 3 & 0.0706 & 0.62 \\
\hline
\end{tabular}

Overall, the ANN and SVM models yield similar prediction results and better prediction performance than MLR models (Figure 4). ANN seems to best predict the water level of the Bosphorus with the highest $R=0.76$ and $R M S E=0.0587$, while SVM is with the highest $R=0.72$ and $R M S E=0.0608$. ANN seems to be the best model to predict the water level of the Bosphorus with the highest $R=0.76$ and $R M S E=0.0587$, while $S V M$ is with the highest $R=0.72$ and $R M S E$ $=0.0608$. However, SVM can be used to forecast the water level of the Bosphorus in some special conditions. It can be seen that Set 4 in Table 3 and Set 10 in Table 4 produce the best models for ANN and SVM, respectively. Set 4 includes WTD, WSD, NWGF, while Set 10 includes WTD, WSD, APF (Table 2). This indicates that ANN is more sensitive to the wind, while SVM is sensitive to the air pressure for Bosphorus Strait. Since Bosphorus Strait shows highly oceanographic variability due to wind effects, atmospheric pressure differences, tide and freshwater, it is a challenging task to improve model prediction capabilities. In the future, the influence of the Danube River with different lag times on sea level prediction can be investigated. In addition, more reliable and robust predictions can be obtained if the dynamic and long-term measurement stations are installed in the Bosphorus. 


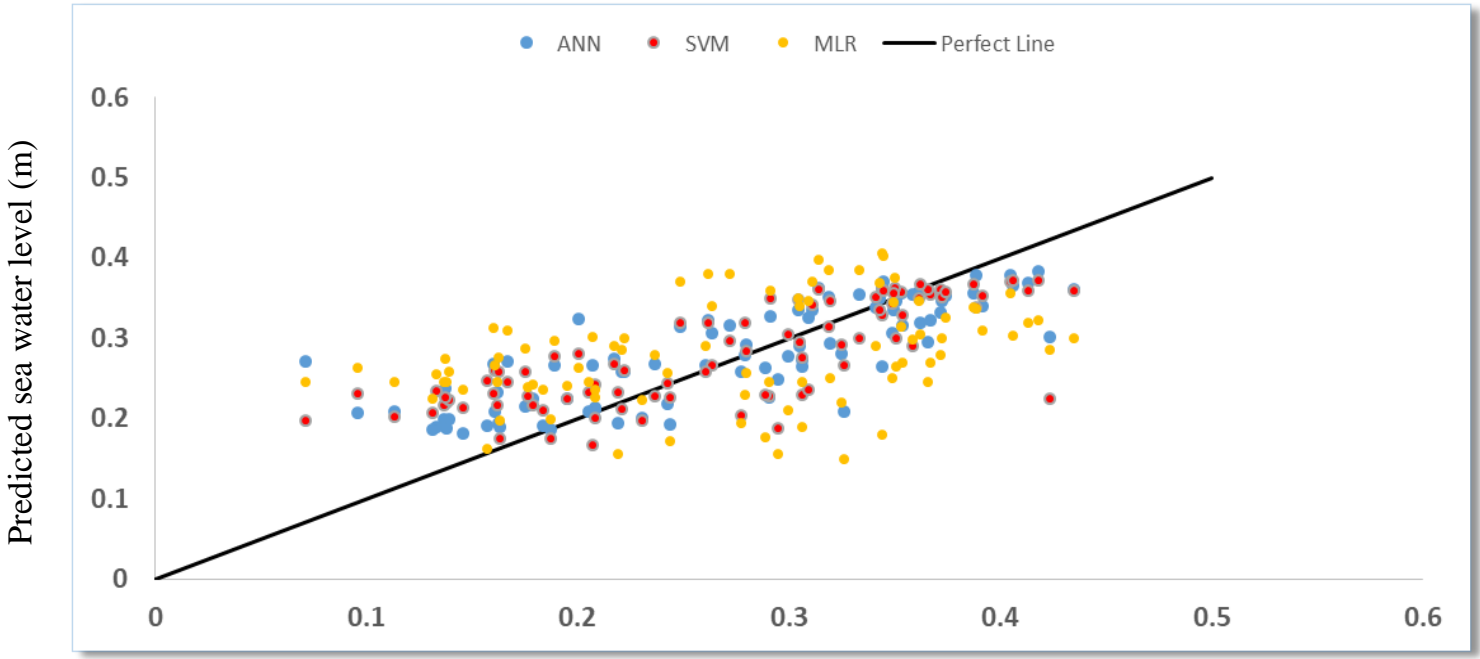

Observed sea water level (m)

Figure 4. Scatter plot of seawater level for ANN and SVM in Bosphorus Strait (together with 1:1 perfect line).

\section{Influence of the Danube River on the Northern Bosphorus}

In the present study, the influence of the Danube River on water surface elevation in the Bosphorus was also investigated by using ANNs. Although there is about $500 \mathrm{~km}$ distance between the Danube River and Bosphorus Strait (Figure 1), there are various studies in the literature revealing the influence of the Danube River on water levels in the Bosphorus. Sur et al. (1994), revealed the lag time from the Danube River to the Bosphorus between 1-2 months. Similar findings are also found by Yuksel et al. (2008) and Karsavran et al. (2020). In the present study, based on the findings of (Karsavran et al., 2020), 70 days lagged Danube River discharge is added to the best ANN model defined with the input structure given in Table 4. Various hidden layer structures are employed. Finally, network structure 4-9-1 (4 input- 9 hidden neuron- 1 output) resulted in the best ANN model. The $\mathrm{R}$ value increased to 0.82 from 0.76 , and the $R M S E$ value decreased to 0.0488 from 0.0587 .

\section{Conclusions}

In the present study, ANN and SVM techniques are applied to predict the daily water levels of the Bosphorus to obtain higher correlation coefficient R. Results indicate that ANN has the best performance to predict the seawater level by $R=0.76$ and $R M S E=0.0587$ in Bosphorus Strait, although SVM approaches the prediction performance of it. However, according to the input sets that provide the best results for ANN and SVM, it is observed that ANN is more sensitive to the wind, while SVM is sensitive to the air pressure.

When the Danube River discharge data are inserted to the best resulted ANN model as an independent input parameter, the correlation coefficient dramatically increases from $R=0.76$ to $R$ $=0.82$ and $R M S E=0.0488$. This reveals the effect of the Danube River run-off discharges to the sea level of Bosphorus Strait. However, it is not possible to get a higher correlation coefficient $(R)$ for the prediction of seawater level of Bosphorus with the observed data due to the chaotic structure of Bosphorus Strait. 
Conflict of Interest

The authors confirm that there is no conflict of interest to declare for this publication.

\section{Acknowledgments}

This research did not receive any specific grant from funding agencies in the public, commercial, or not-for-profit sectors. The authors would like to thank the editor and anonymous reviewers for their comments that help improve the quality of this work.

\section{References}

Altunkaynak, A. (2014). Predicting water level fluctuations in lake michigan-huron using wavelet-expert system methods. Water Resources Management, 28(8), 2293-2314.

Altunkaynak, A. (2019). Predicting water level fluctuations in Lake Van using hybrid season-neuro approach. Journal of Hydrologic Engineering, 24(8), 04019021.

Altunkaynak, A., \& Kartal, E. (2019). Performance comparison of continuous wavelet-fuzzy and discrete wavelet-fuzzy models for water level predictions at northern and southern boundary of Bosphorus. Ocean Engineering, 186, 106097. https://doi.org/10.1016/j.oceaneng.2019.06.002.

Altunkaynak, A., \& Kartal, E. (2021). Transfer sea level learning in the Bosphorus strait by wavelet based machine learning methods. Ocean Engineering, 233, 109116. https://doi.org/10.1016/j.oceaneng.2021.109116.

Altunkaynak, A., \& Sen, Z. (2007). Fuzzy logic model of Lake water level fluctuations in Lake Van, Turkey. Theoretical and Applied Climatology, 90(3), 227-233. https://doi.org/10.1007/s00704-006-0267-z.

Altunkaynak, A., Ozger, M., \& Sen, Z. (2003). Triple diagram model of level fluctuations in lake van, Turkey. Hydrology and Earth System Sciences, 7(2), 235-244. https://doi.org/10.5194/hess-7-235-2003, 2003.

Anderson, S.J. (2013). Optimizing HF radar siting for surveillance and remote sensing in the Strait of Malacca. IEEE Transactions on Geoscience and Remote Sensing, 51(3), 1805-1816.

ASCE Task Committee on Application of Artificial Neural Networks in Hydrology. (2000). Artificial neural networks in hydrology. I: preliminary concepts. Journal of Hydrologic Engineering, 5(2), 115-123.

Chau, K.W., \& Cheng, C.T. (2002, December). Real-time prediction of water stage with artificial neural network approach. In Australian Joint Conference on Artificial Intelligence, (pp. 715-715). Springer, Berlin, Heidelberg. https://doi.org/10.1007/3-540-36187-1_64.

Dibike, Y.B., Velickov, S., Solomatine, D., \& Abbott, M.B. (2001). Model induction with support vector machines: introduction and applications. Journal of Computing in Civil Engineering, 15(3), 208-216.

Duan, Q.Y., Gupta, V.K., \& Sorooshian, S. (1993). Shuffled complex evolution approach for effective and efficient global minimization. Journal of Optimization Theory and Applications, 76(3), 501-521.

Erdik, T., \& Pektas, A.O. (2019). Rock slope damage level prediction by using multivariate adaptive regression splines (MARS). Neural Computing and Applications, 31(7), 2269-2278.

Erdik, T., Savci, M.E., \& Sen, Z. (2009). Artificial neural networks for predicting maximum wave runup on rubble mound structures. Expert Systems with Applications, 36(3, part 2), 6403-6408.

Ergocun, G. (2019). Over 41,000 vessels pass through Bosphorus in 2019, Anadolu Agency, https://www.aa.com.tr/en/economy/over-41-000-vessels-pass-through-bosphorus-in-2019/1722573.

Hil, G. (2020). Better management through measurement: integrating archaeological site features into a GISbased erosion and sea level rise impact assessment-blueskin bay, New Zealand. The Journal of Island and Coastal Archaeology, 15(1), 104-126. https://doi.org/10.1080/15564894.2018.1531331. 
Jarosz, E., Teague, W.J., Book, J.W., \& Beşiktepe, S. (2011). Observed volume fluxes in the Bosphorus strait. Geophysical Research Letters, 38(21), 1-6. https://doi.org/10.1029/2011GL049557.

Karimi, S., Kisi, O., Shiri, J., \& Makarynskyy, O. (2013). Neuro-fuzzy and neural network techniques for forecasting sea level in darwin harbor, Australia. Computers \& Geosciences, 52, 50-59.

Karsavran, Y., Erdik, T., \& Terzioglu, Z.O. (2020). The effect of the peak discharges of river danube on Istanbul strait (Bosphorus). International Journal of Environment and Geoinformatics, 7(2), 108-113.

Khaledian, M.R., Isazadeh, M., Biazar, S.M., \& Pham, Q.B. (2020). Simulating caspian sea surface water level by artificial neural network and support vector machine models. Acta Geophysica, 68(3-4), 553563. https://doi.org/10.1007/s11600-020-00419-y.

Kim, M.H., Kim, Y.S., Lim, J., Kim, J.T., Sung, S.W., \& Yoo, C. (2010). Data-driven prediction model of indoor air quality in an underground space. Korean Journal of Chemical Engineering, 27(6), 1675-1680.

Kim, S., Shiri, J., Kisi, O., \& Singh, V.P. (2013). Estimating daily pan evaporation using different data-driven methods and lag-time patterns. Water Resources Management, 27(7), 2267-2286.

Kisi, O. (2007). Streamflow forecasting using different artificial neural network algorithms. Journal of Hydrologic Engineering, 12(5), 532-539.

Kisi, O., \& Cigizoglu, H.K. (2007). Comparison of different ANN techniques in river flow prediction. Civil Engineering and Environmental Systems, 24(3), 211-231. https://doi.org/10.1080/10286600600888565.

Lin, C.T., \& Lee, C.G. (1996). Neural fuzzy systems: a neuro-fuzzy synergism to intelligent systems. Prentice hall.

Lin, G.Q., Li, L.L., Tseng, M.L., Liu, H.M., Yuan, D.D., \& Tan, R.R. (2020). An improved moth-flame optimization algorithm for support vector machine prediction of photovoltaic power generation. Journal of Cleaner Production, 253, 119966. https://doi.org/10.1016/j.jclepro.2020.119966.

Lin, J.Y., Cheng, C.T., \& Chau, K.W. (2006). Using support vector machines for long-term discharge prediction. Hydrological Sciences Journal, 51(4), 599-612. https://doi.org/10.1623/hysj.51.4.599.

Maderich, V., \& Konstantinov, S. (2002). Seasonal dynamics of the system sea-strait: Black Sea-Bosphorus case study. Estuarine, Coastal and Shelf Science, 55(2), 183-196.

Makarynska, D., \& Makarynskyy, O. (2008). Predicting sea-level variations at the cocos (keeling) islands with artificial neural networks. Computers \& Geosciences, 34(12), 1910-1917.

Montgomery, D.C., Runger, G.C., \& Hubele, N.F. (2009). Engineering statistics. John Wiley \& Sons.

Okcu, D., Pektas, A.O., \& Uyumaz, A. (2016). Creating a non-linear total sediment load formula using polynomial best subset regression model. Journal of Hydrology, 539, 662-673.

Ozsoy, E., Latif, M.A., Besiktepe, S.T., Cetin, N., Gregg, M.C., Belokopytov, V., Goryachkin, Y., \& Diaconu, V. (1998). The Bosphorus Strait: Exchange fluxes, currents, and sea-level changes, in Ecosystem Modeling as a Management Tool for the Black Sea, edited by L. Ivanov, and T. Oğuz, NATO Sci. Ser., 2, 1- 27, Kluwer Acad., Dordrecht, Netherlands.

Pethick, J. (2001). Coastal management and sea-level rise. Catena, 42(2-4), 307-322. https://doi.org/10.1016/S0341-8162(00)00143-0.

RTMEU, (2005). Long-term continuous current velocity measurements. Republic of Turkey Ministry of Environment and, Urbanization.

Sacu, S., Erdik, T., \& Sen, O. (2020b). Salinity distribution at canal Istanbul and its possible impacts on the northern marmara sea. China Ocean Engineering, 34(6), 881-888. https://doi.org/10.1007/s13344-0200080-y. 
Sacu, S., Erdik, T., Stanev, E.V., Sen, O., Erdik, J.D., \& Öztürk, İ. (2020a). Hydrodynamics of canal Istanbul and its impact in the northern sea of Marmara under extreme conditions. Ocean Dynamics, 70(6), 745758. https://doi.org/10.1007/s10236-020-01358-4.

Sacu, S., Sen, O., \& Erdik, T. (2021). A stochastic assessment for oil contamination probability: a case study of the Bosphorus. Ocean Engineering, 231, 109064. https://doi.org/10.1016/j.oceaneng.2021.109064.

Sen, Z., \& Erdik, T. (2010). Discussion of "improvement of regression simulation in fluvial sediment loads" by P. Wang and L.C Linker. Journal of Hydraulic Engineering, 136(3), 191-192.

Seo, Y., Kim, S., Kisi, O., \& Singh, V.P. (2015). Daily water level forecasting using wavelet decomposition and artificial intelligence techniques. Journal of Hydrology, 520, 224-243.

Sertel, E., Cigizoglu, H.K., \& Sanli, D.U. (2008). Estimating daily mean sea level heights using artificial neural networks. Journal of Coastal Research, 24(3 (243)), 727-734.

Smith, R.B. (2015). Dynamical meteorology| hydraulic flow. In book: Encyclopedia of Atmospheric Sciences. 332-333. https://doi.org/10.1016/B978-0-12-382225-3.00165-1.

Sur, H.I., Ozsoy, E., \& Unluata, U. (1994). Boundary current instabilities, upwelling, shelf mixing and eutrophication processes in the Black Sea. Progress in Oceanography, 33(4), 249-302.

Vapnik, V.N. (1995). The nature of statistical learning theory. Springer, New York. https://doi.org/10.1007/978-1-4757-2440-0.

Vapnik, V.N. (1998). Statistical learning theory. Wiley, New York.

Wang, W.C., Chau, K.W., Cheng, C.T., \& Qiu, L. (2009). A comparison of performance of several artificial intelligence methods for forecasting monthly discharge time series. Journal of Hydrology, 374(3-4), 294-306. https://doi.org/10.1016/j.jhydrol.2009.06.019.

Whittington, M. (2016). Identifying and assessing emerging risks in marine transportation.

Yuksel, Y., Ayat, B., Ozturk, M.N., Aydogan, B., Guler, I., Cevik, E.O., \& Yalçıner, A.C. (2008). Responses of the stratified flows to their driving conditions - a field study. Ocean Engineering, 35(13), 1304-1321. 